\title{
USE OF A SPOT TEST FOR CHLORIDE IN CERVICAL MUCUS FOR SELF-DETECTION OF THE FERTILE PHASE IN WOMEN*
}

\author{
N. R. HARDY, LINDA LEWIS, VALERIE LITTLE \\ AND G. I. M. SWYER \\ University College Hospital Medical School, London
}

(Received 15th May 1969)

\begin{abstract}
Summary. A study of the correlation between a positive spot test for chloride in cervical mucus and the occurrence of ovulation, as indicated by the peak of the karyopycnotic index in the vaginal smear, has been made. The brightest positive spot coincides with, or occurs a few days before, the probable day of ovulation - too late to be of value for contraception by the rhythm method but of potential value to couples desiring conception, especially as the woman can easily use the test herself. Anovulatory patients treated with gonadotrophins show a positive chloride spot when the ovary responds to follicle-stimulating hormone.
\end{abstract}

\section{INTRODUCTION}

It has long been known that human cervical mucus undergoes cyclic changes and that these are mediated by the ovarian hormones (Séguy \& Vimeux, 1933; Séguy \& Simmonet, 1933). Characteristic physico-chemical changes are induced by oestrogens leading to the production of copious, clear, watery mucus at the time of ovulation, coinciding with the peak of oestrogen secretion which then occurs. Following this, under the influence of progesterone secreted by the corpus luteum, the mucus quickly becomes thick, tacky and cellular and its quantity diminishes. The possibility of using these changes as a means of detecting or predicting the occurrence of ovulation has appealed to a number of workers who have studied various physical and chemical properties, among which interest has centred particularly on chloride ions. Though the concentration of sodium chloride remains almost constant and isotonic (Bergman \& Lund, 1950), the percentage of $\mathrm{NaCl}$ in dry mucus shows pronounced variations during the cycle (Herzberg, Joel \& Katchalsky, 1964) with a sharp maximum at ovulation. The peak concentration of $\mathrm{NaCl}$ in dry mucus coincides with the phenomenon of fern-like crystallization of mucus on a glass slide (Campos da Paz, 1951) which requires the presence of mucin-like substances as well as $\mathrm{NaCl}$ in high concentration.

The use of silver chromate paper for the development of a simple 'spot' test

* Part of a thesis for the degree of Master of Philosophy to be presented by L.L. to the University of London. 

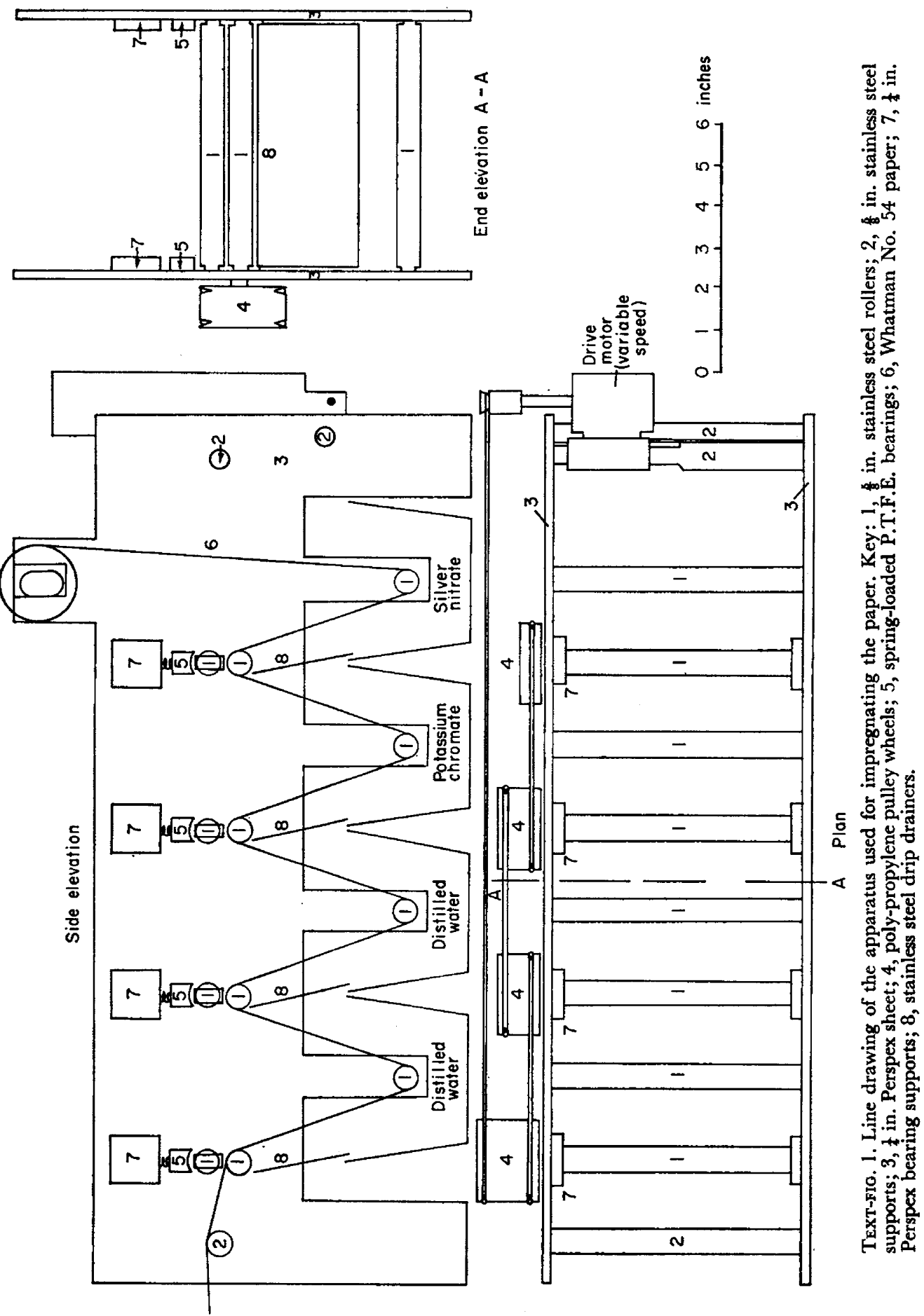
for detection of ovulation by determination of the chloride content of cervical mucus was studied by McSweeney \& Sbarra (1964) and, while working on other possible methods of detecting ovulation, we have used a modification of this spot test, run in parallel with other investigations. The results obtained from a study of sixty cycles in apparently normal women and of five amenorrhoeic patients treated with gonadotrophins to induce ovulation are presented.

\section{MATERIALS AND METHODS}

\section{Silver chromate paper}

This was prepared from a strip of Whatman filter paper, grade $54,12.5 \mathrm{~cm}$ wide, immersed serially in solutions of silver nitrate $(0.275 \mathrm{M})$ and potassium chromate $(0.175 \mathrm{M})$ by means of an apparatus constructed for the purpose

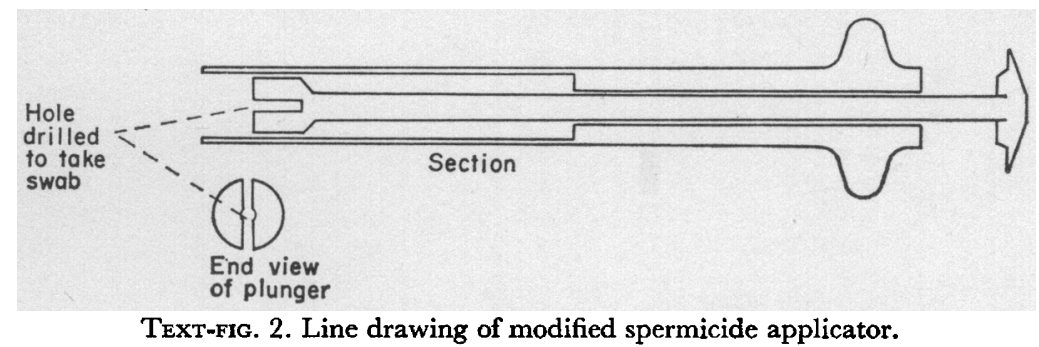

(Text-fig. 1; Pl. 1, Fig. 1). The paper was then washed twice in distilled water and dried in air, cut into pieces $12.5 \mathrm{~cm}$ long and marked off into numbered squares with a rubber stamp.

Cervical mucus (obtained as described below) was spotted daily on to consecutive squares on the paper and the dried spots were compared with a set of standards (Pl. 1, Fig. 2) to estimate the chloride content of the mucus. Experience showed that, while high concentrations of chloride $(0.5 \%$ and over) could easily be differentiated from low concentrations $(0.4 \%$ and less), it was difficult to estimate the absolute concentration. Nevertheless, the differentiation between these two levels, called positive and negative respectively, was generally not difficult and enabled one to tell when a significant change had occurred.

\section{Collection of specimens}

Each subject was supplied with an ovulation thermometer (Zeal), temperature chart, modified spermicide applicator (British Drug Houses), box of cotton buds (Johnson \& Johnson), box of glass slides with ground ends, carbowax fixative in a dropper bottle and a sheet of silver chromate paper.

The spermicide applicators were modified as shown in Text-fig. 2 so that half of a double-ended cotton wool swab fitted firmly into the end of the plunger. The plunger with swab inserted was drawn back into the barrel of the applicator which was gently pushed by the subject into her vagina as far as possible. The applicator was then withdrawn about $2 \mathrm{~cm}$ and the plunger pushed in to expose the swab; this was rotated to wipe a sample of mucus from the vicinity of the cervix. The plunger was pulled back into the barrel and the applicator withdrawn. A slide was wiped with a tissue and the subject wrote her name and 


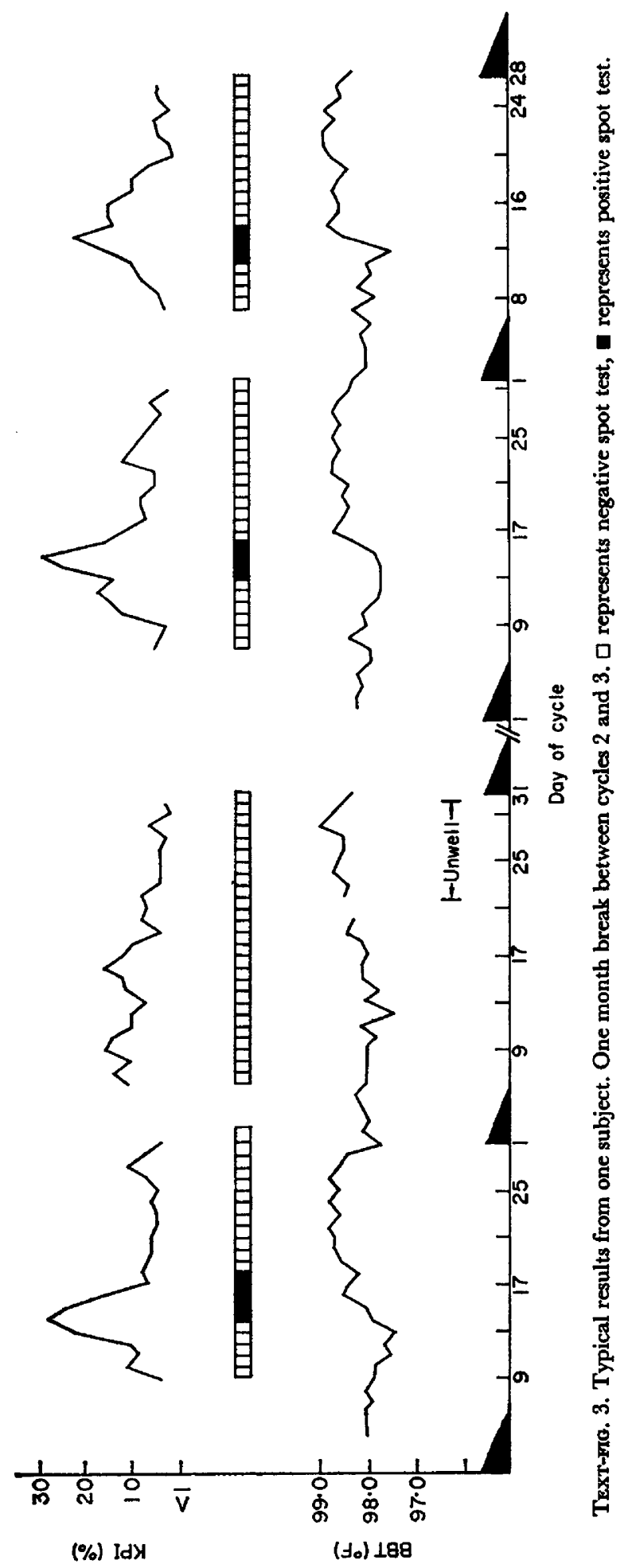


the date on the ground end in pencil. The cotton wool swab was exposed and rolled on the slide, fixative being dropped immediately on to the smear which was then allowed to dry in air.

The remaining mucus on the swab was spotted on the appropriate square of the silver chromate paper.

Determination of karyopycnotic index (KPI)

The slides were stained by a modified Papanicolaou technique and mounted in crystal mountant. They were examined by phase-contrast microscopy in

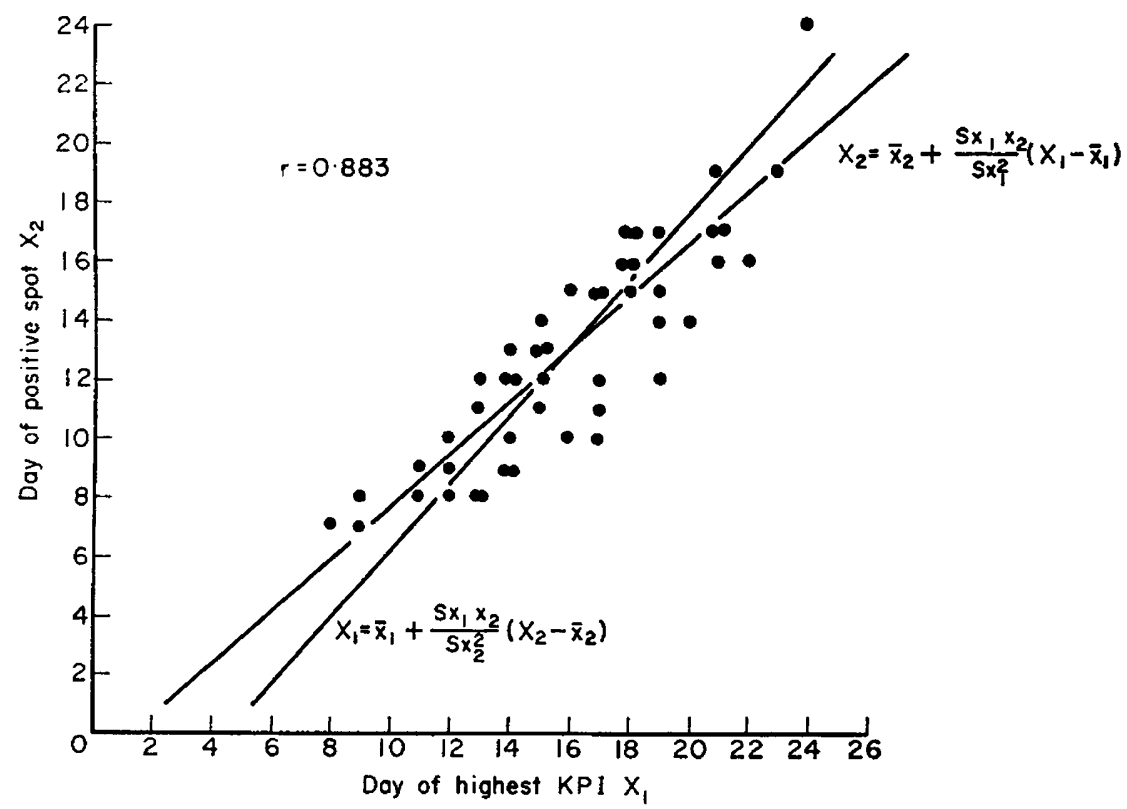

TeXT-FIG. 4. Correlation between day of first positive spot and day of highest KPI.

which pycnotic nuclei appear as shining red bodies (Wied, 1955). One hundred cells of superficial or intermediate type were examined in each of two areas and the percentage with pycnotic nuclei was noted.

\section{Subjects}

The subjects included eleven volunteers, aged between 20 and 30, who recorded their basal body temperatures (BBT) and made vaginal smears and cervical mucus chloride spot tests, as described above, daily throughout the menstrual cycle. A similar regimen was followed by five patients attending the Fertility Glinic at University College Hospital, who were under treatment with gonadotrophins for failure of ovulation.

Normal cycles

\section{RESULTS}

Fifty cycles in eleven women with apparently normal menstruation were studied by BBT, KPI and chloride spot test. Text-figure 3 shows some typical 


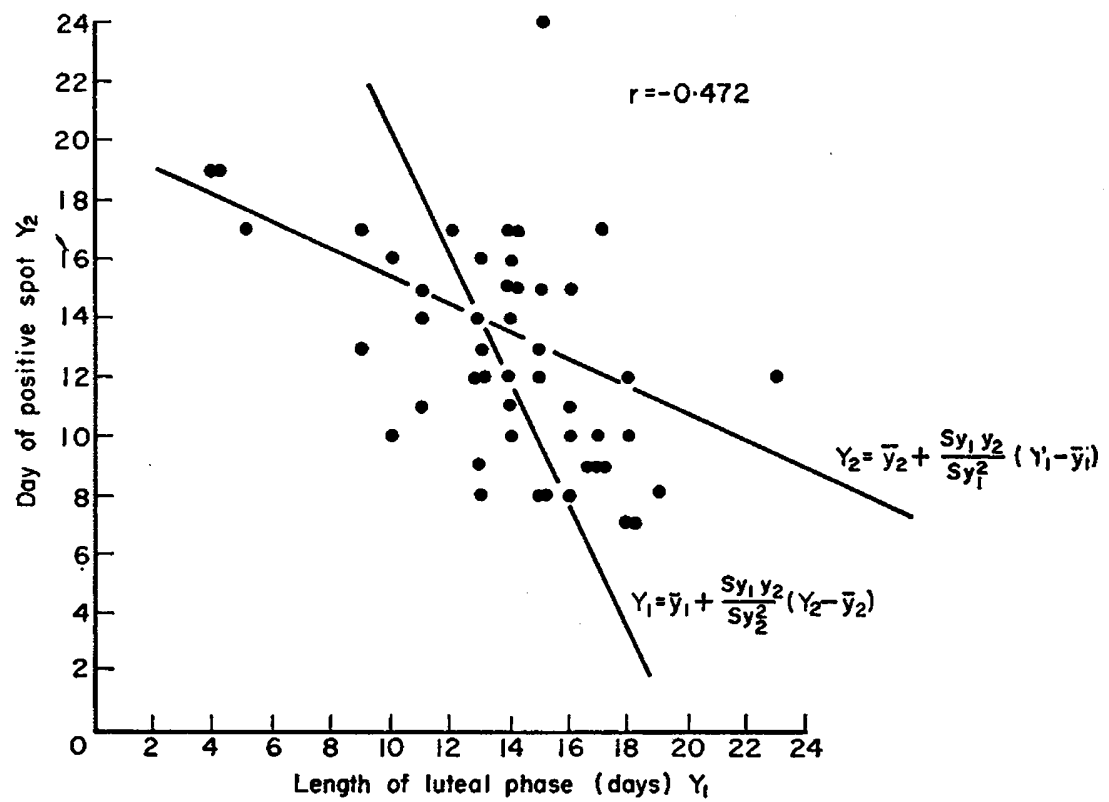

Text-Fic. 5. Correlation between day of first positive spot and length of luteal phase.

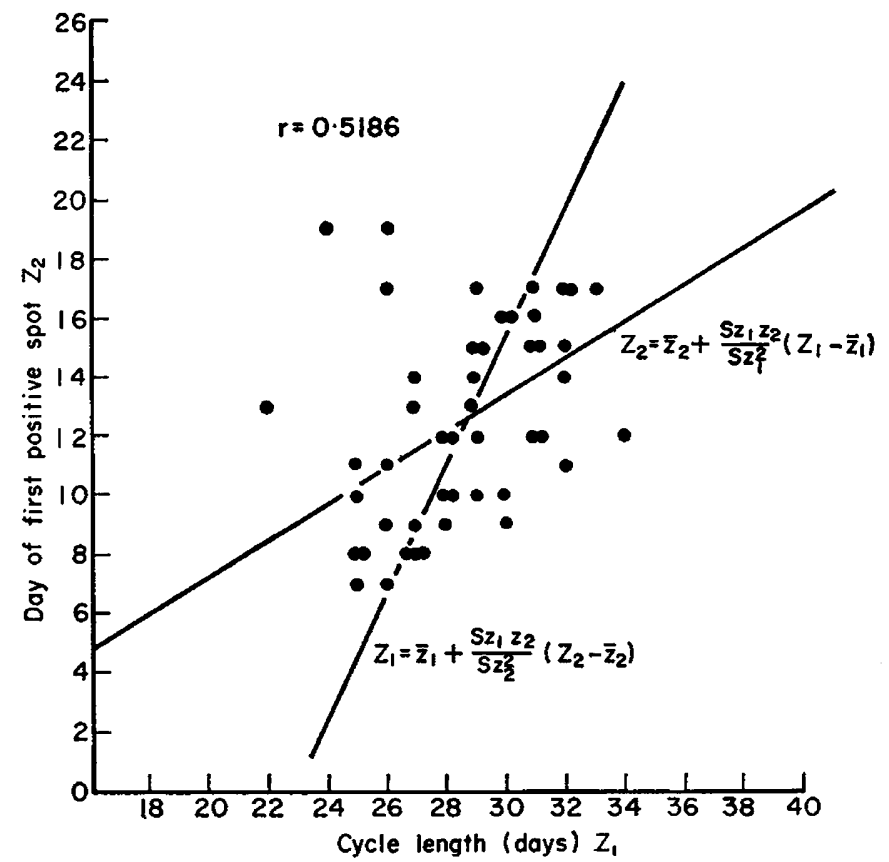

Texr-pic. 6. Correlation between day of first positive spot and whole cycle length. 


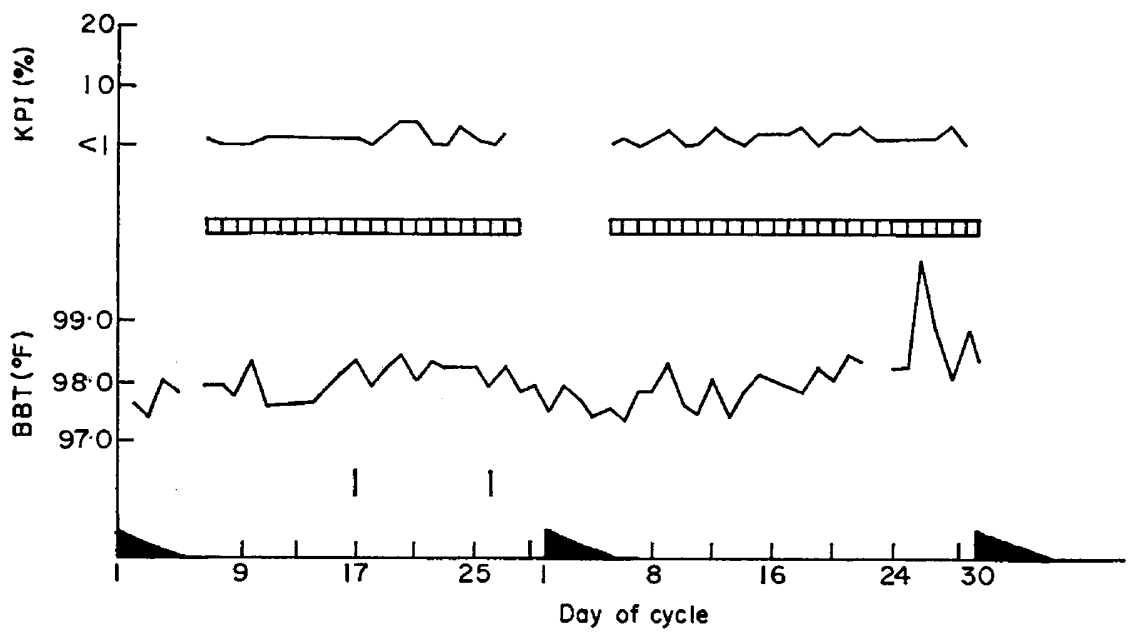

TEXT-FIG. 7. Typical results from one subject presumed to have consistent anovulatory cycles. ( $\square$ represents negative spot test).
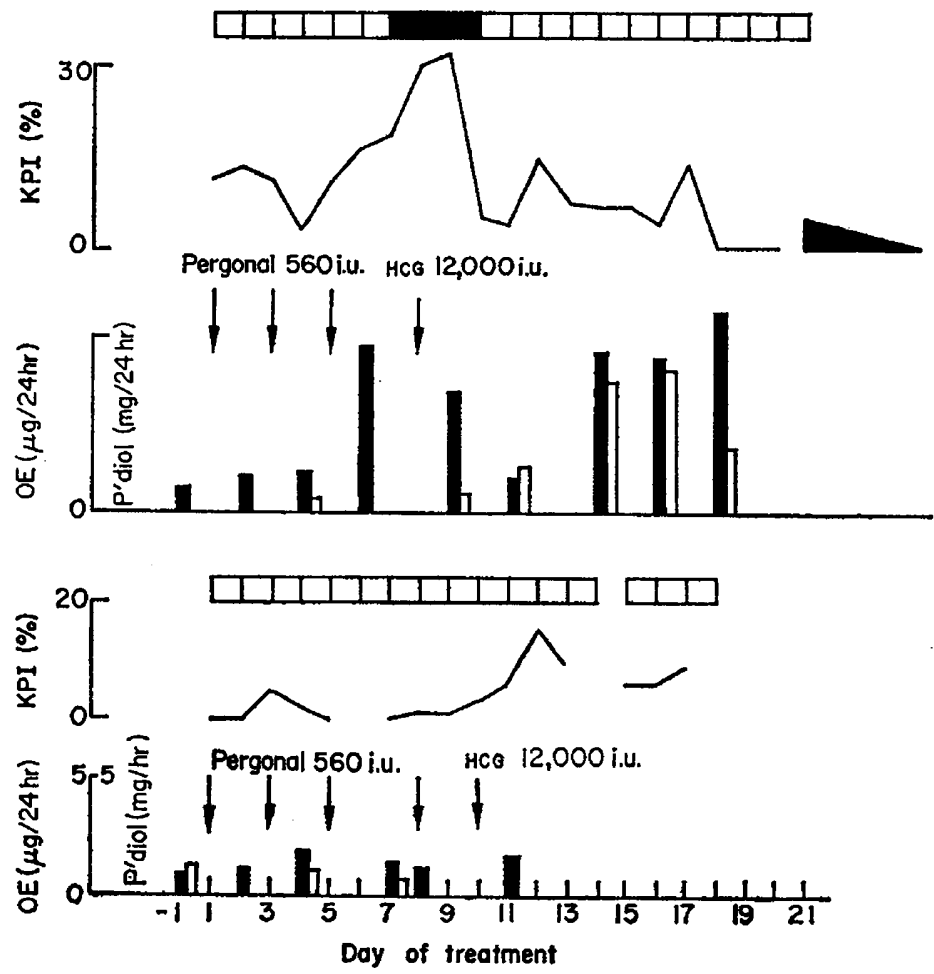

TexT-Fig. 8. Results from two patients treated with Pergonal and HCG where no pregnancy ensued. The upper chart shows a luteal response. ( $\square$ represents negative spot test, represents positive spot test, oestrone (OE) represented by closed histogram, pregnanediol (P'diol) by the open histogram). 

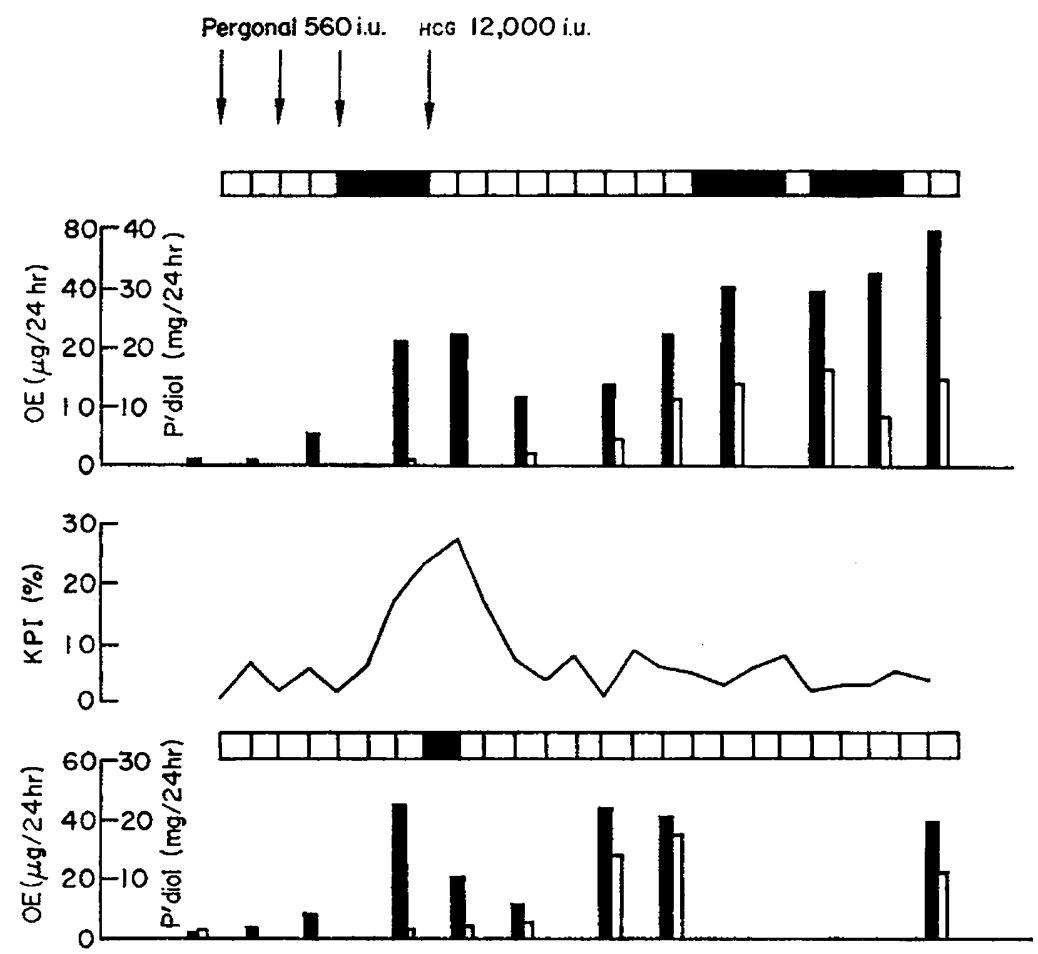

$$
\stackrel{0}{\frac{a}{3}}^{20} 10-
$$
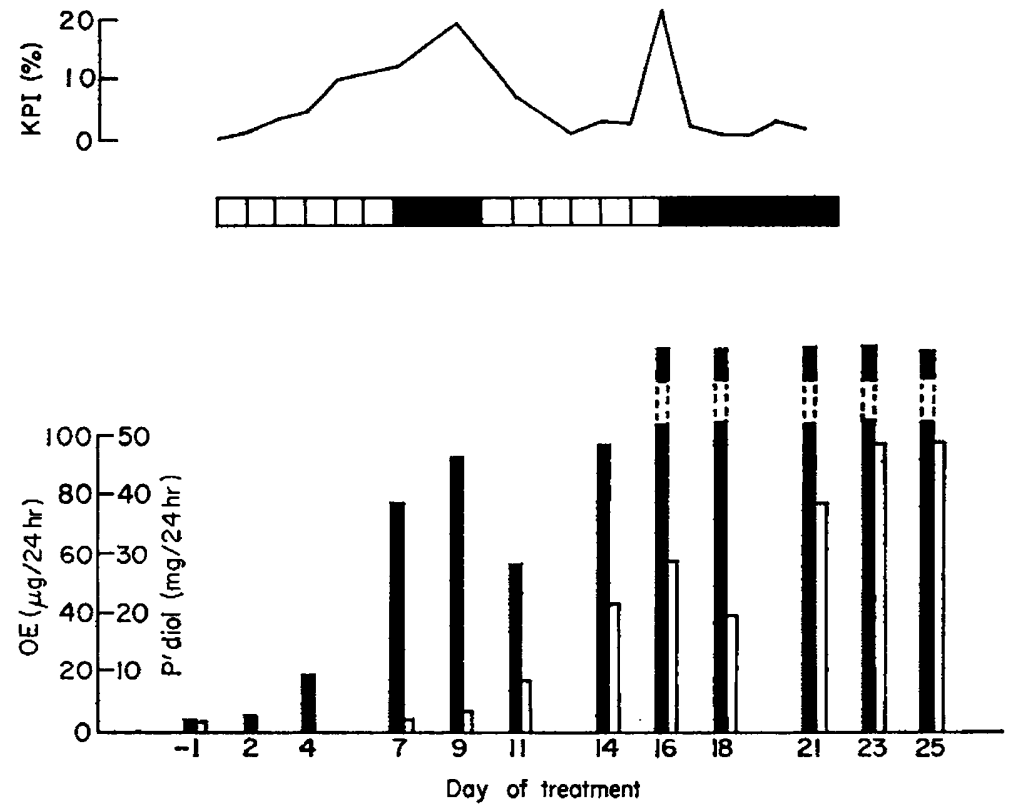

TEXT-Fig. 9. Results from three patients who conceived following treatment with Pergonal and HCG. Graphic representations as in Text-fig. 8. 
Pl. IIE I
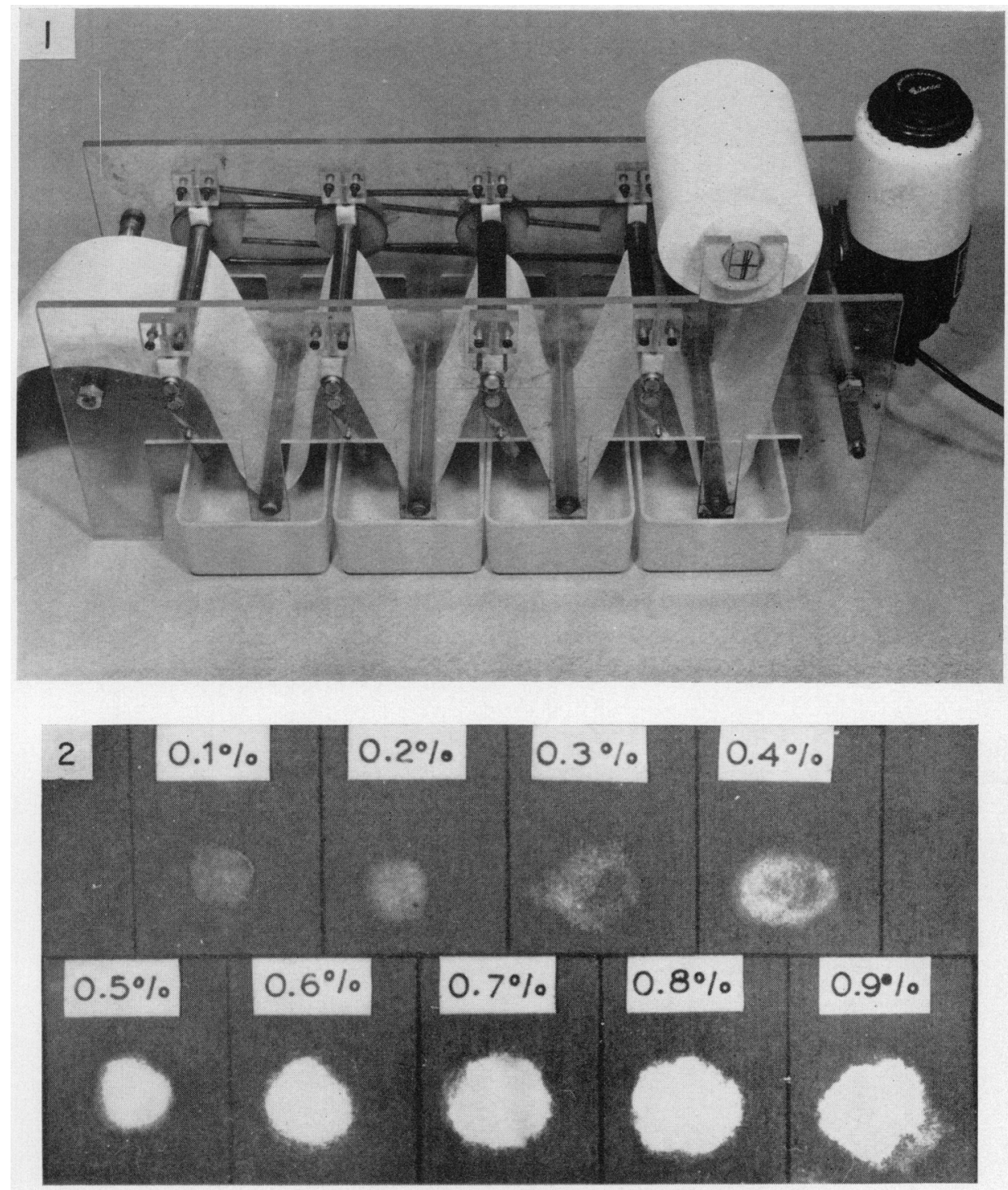

lici. 1. Apparatus used for impregnating the paper.

Fic. 2. Standards used for assessment of test sheets. 


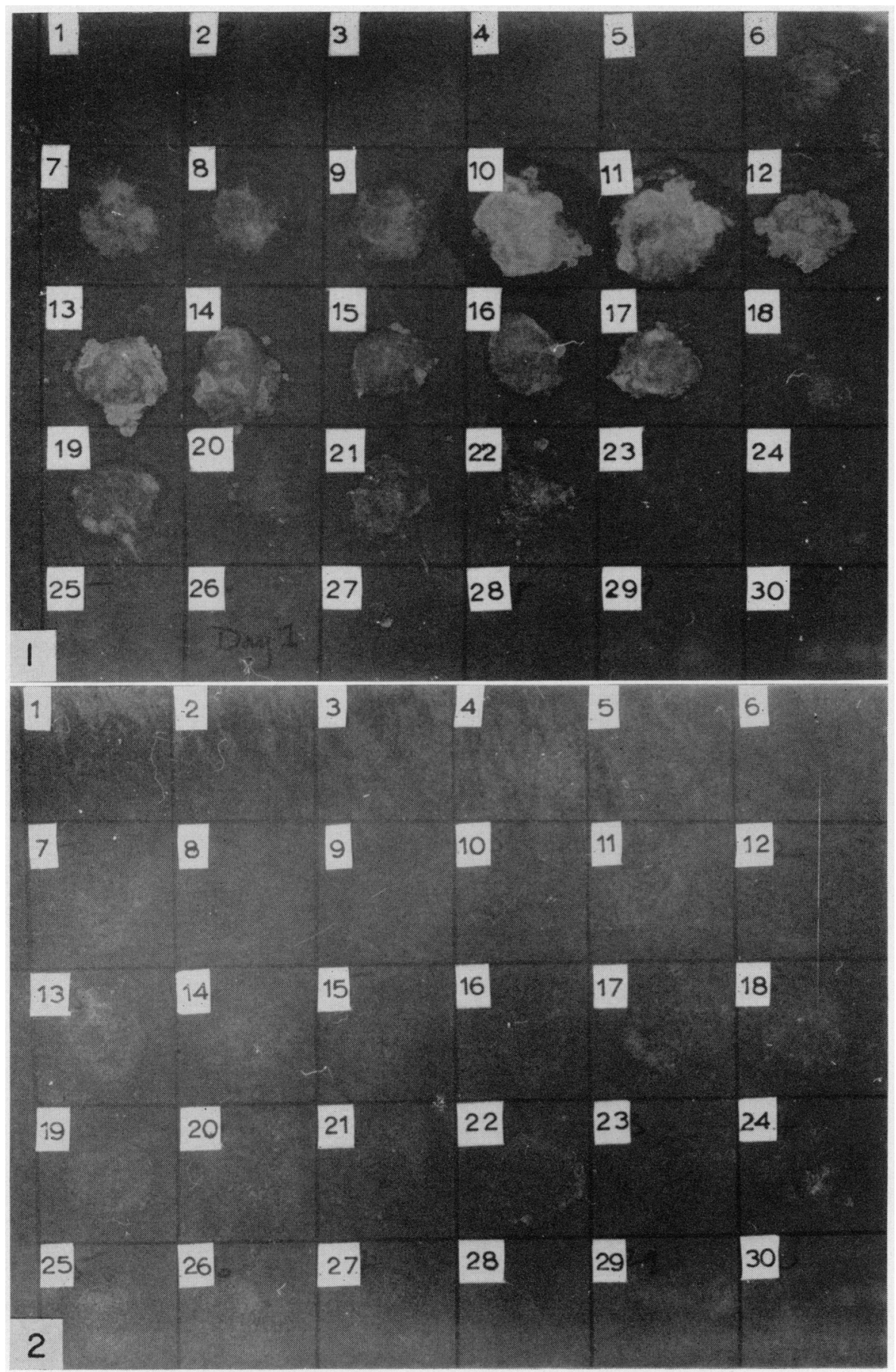

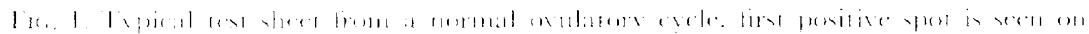
11,1111

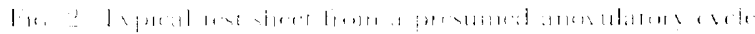


results from one subject represented graphically. The first, third and fourth cycles appear to be normal ovulatory cycles, with characteristic biphasic BBT, peaks of KPI and positive spot tests. A typical test sheet is shown in Pl. 2, Fig. l. The second cycle, on the other hand, shows no peak of KPI, no positive spot test and an atypical BBT; it is presumed to have been anovulatory.

The relationship between the day of the first positive spot and that of the highest KPI, length of luteal phase and length of the whole cycle was studied by determining the three correlation coefficients (Text-figs. 4, 5 and 6). In all three, $P<0.001$.

\section{Abnormal cycles}

Eleven cycles were considered to be anovulatory because there was no peak of KPI and BBTs were not biphasic. Text-figure 3, cycle 2 and Text-fig. 7 show examples. Plate 2, Fig. 2 illustrates a typical test sheet obtained from such a cycle. These cycles were excluded from the calculation of correlation coefficients referred to above.

\section{Patients treated with gonadotrophins}

These patients, aged 27 to 39 , were given intramuscular injections of human menopausal gonadotrophin (Pergonal) to stimulate follicle development, followed by human chorionic gonadotrophin (HCG) to induce ovulation from the ripe follicle. The response was monitored by urinary oestrone and pregnanediol determinations on 24-hr urine specimens and examination of the patients, as well as by evaluation of the KPI and chloride spot tests.

Text-figure 8 shows the absence of a positive chloride spot in a patient who failed to respond to Pergonal and a positive spot test in another who responded, apparently with ovulation, to Pergonal followed by HCG.

Text-figure 9 shows the findings in three patients who conceived when treated with Pergonal and HCG. When there was a response to treatment, a positive spot appeared on about Day 5 or 6 (counting the day of the first Pergonal injection as Day 1).

\section{DISCUSSION}

The object of this investigation was to see whether the chloride spot test with cervical mucus could indicate the day of ovulation and the evidence presented suggests that it can, in at least a proportion of women with normal cycles. Like the KPI, the mid-cycle peak of which coincides closely with the day of the brightest positive chloride spot, the latter probably indicates, or just antedates, the day of ovulation. This is in contrast to the rise in BBT which post-dates it and so provides no guide for the timing of coitus intended to result in conception. Unlike the KPI, the chloride spot test gives an instant result and is readily carried out by the patient herself.

The correlation between the day of the first positive chloride spot and the day of the highest KPI was excellent. In every cycle studied, the temperature rise occurred either on the supposed day of ovulation or afterwards, sometimes several days afterwards. Positive chloride spots appeared either before or on the 
supposed day of ovulation and in some cases persisted until after the temperature rise had occurred. In cases where there were many positive spots, it was often possible to differentiate degrees of brightness, especially where the reaction had penetrated through the paper so that a white spot could be seen on the back. In these cases, the first penetrating spot was regarded as the first positive one. Though there was wide variation in the type and intensity of spots from the different volunteers, the type for a given individual tended to be constant.

In this study, the interpretation of the spots was made by the investigators and so the ability of the volunteers to distinguish the positive spots was not important. They were, in fact, able to do so and this would be important for patients using the test themselves as a guide to the fertile phase of the cycle.

The studies on the patients treated with gonadotrophins show a clear correlation of the appearance of a positive spot with ovarian response to folliclestimulating hormone. The spot becomes negative after ovulation is induced with HCG but, in two of the patients who conceived, became positive again as the oestrogen level rose in the later luteal phase. An obvious correlation exists between the spot test and the oestrogen level, as measured in these patients by urinary oestrone excretion.

Originally, the chloride spot test had been studied as a possible aid to the rhythm method of contraception but for this purpose it proved ineffective because the first positive spot does not occur early enough before ovulation. However, for indicating the imminence of ovulation as an aid to conception, the test shows considerable promise; its use for this purpose by infertile couples is currently under investigation.

\section{ACKNOWLEDGMENTS}

This work was supported by a grant to Dr G. I. M. Swyer from the World Health Organization to which acknowledgment is gratefully made. We wish to thank Mr H. J. Shah for carrying out the oestrone and pregnanediol estimations.

\section{REFERENCES}

Bergman, P. \& Lund, G. G. (1950) The osmotic pressure of human cervical mucus: cyclic changes in osmotic pressure of cervical mucus and effect of osmotic changes on spermatozoal motility. Acta obstet. gynec. scand. 30, 267.

CAMpos DA PAZ, A. (1951) Studies on crystallization of cervical mucus and its relationship to cervical receptivity to spermatozoa. Am. F. Obstet. Gynec, 61A, 790. (Suppl.).

Herzberg, M., Joes, C. A. \& Katchalsky, A. (1964) The cyclic variation of sodium chloride content in the mucus of the cervix uteri. Fert. Steril. 15, 684.

McSweeney, D. J. \& Sbarra, A. J. (1964) A new cervical mucus test for hormone appraisal. Am. $\mathcal{F}$. Obstet. Gynec. 88, 705.

SÉguy, J. \& Simmonet, H. (1933) Récherche des signes directs de l'ovulation chez la femme. Gynéc. Obstét. 28, 657 .

SÉGUY, J. \& VIMEUX, J. (1933) Contribution à l'étude des stérilités inexpliqués: étude de l'ascension des spermatozoìdes dans les voies génitales basses de la femme. Gynéc. Obstét. 27, 346.

WIED, G. L. (1955) Suggested standard for karyopyknosis. Use in hormonal reading of vaginal smears. Fert. Steril. 6, 61 . 